\title{
Local buckling of composite channel columns
}

Received: 2 February 2018 / Accepted: 26 April 2018 / Published online: 8 May 2018

(C) The Author(s) 2018

\begin{abstract}
The investigation concerns local buckling of compressed flanges of axially compressed composite channel columns. Cooperation of the member flange and web is taken into account here. The buckling mode of the member flange is defined by rotation angle a flange about the line of its connection with the web. The channel column under investigation is made of unidirectional fibre-reinforced laminate. Two approaches to member orthotropic material modelling are performed: the homogenization with the aid of theory of mixture and periodicity cell or homogenization upon the Voigt-Reuss hypothesis. The fundamental differential equation of local buckling is derived with the aid of the stationary total potential energy principle. The critical buckling stress corresponding to a number of buckling half-waves is assumed to be a minimum eigenvalue of the equation. Some numerical examples dealing with columns are given here. The analytical results are compared with the finite element stability analysis carried out by means of ABAQUS software. The paper is focused on a close analytical solution of the critical buckling stress and the associated buckling mode while the web-flange cooperation is assumed.
\end{abstract}

Keywords Fibre composites $\cdot$ Channel column - Analytical solution $\cdot$ FEM

\section{List of symbols}

A Column cross-section area

$b \quad$ Flange width

$D_{1} \quad$ Modulus of elasticity in longitudinal direction

$D_{\mathrm{t}} \quad$ Modulus of elasticity in transverse direction

$E_{\mathrm{f}} \quad$ Modulus of elasticity of fibre

$E_{\mathrm{m}} \quad$ Modulus of elasticity of matrix

$E_{1} \quad$ Young's modulus of elasticity in longitudinal direction

$E_{\mathrm{t}} \quad$ Young's modulus of elasticity in transverse direction

$G \quad$ Shear modulus

Communicated by Francesco dell'Isola.

\section{Szymczak}

Department of Structural Engineering, Faculty of Ocean Engineering and Ship Technology, Gdańsk University of Technology, G. Narutowicza 11/12 13, 80-233 Gdańsk, Poland

E-mail: szymcze@pg.edu.pl

M. Kujawa $(\varangle)$

Department of Structural Mechanics, Faculty of Civil and Environmental Engineering, Gdańsk University of Technology,

G. Narutowicza 11/12 13, 80-233 Gdańsk, Poland

E-mail: mark@pg.edu.pl 


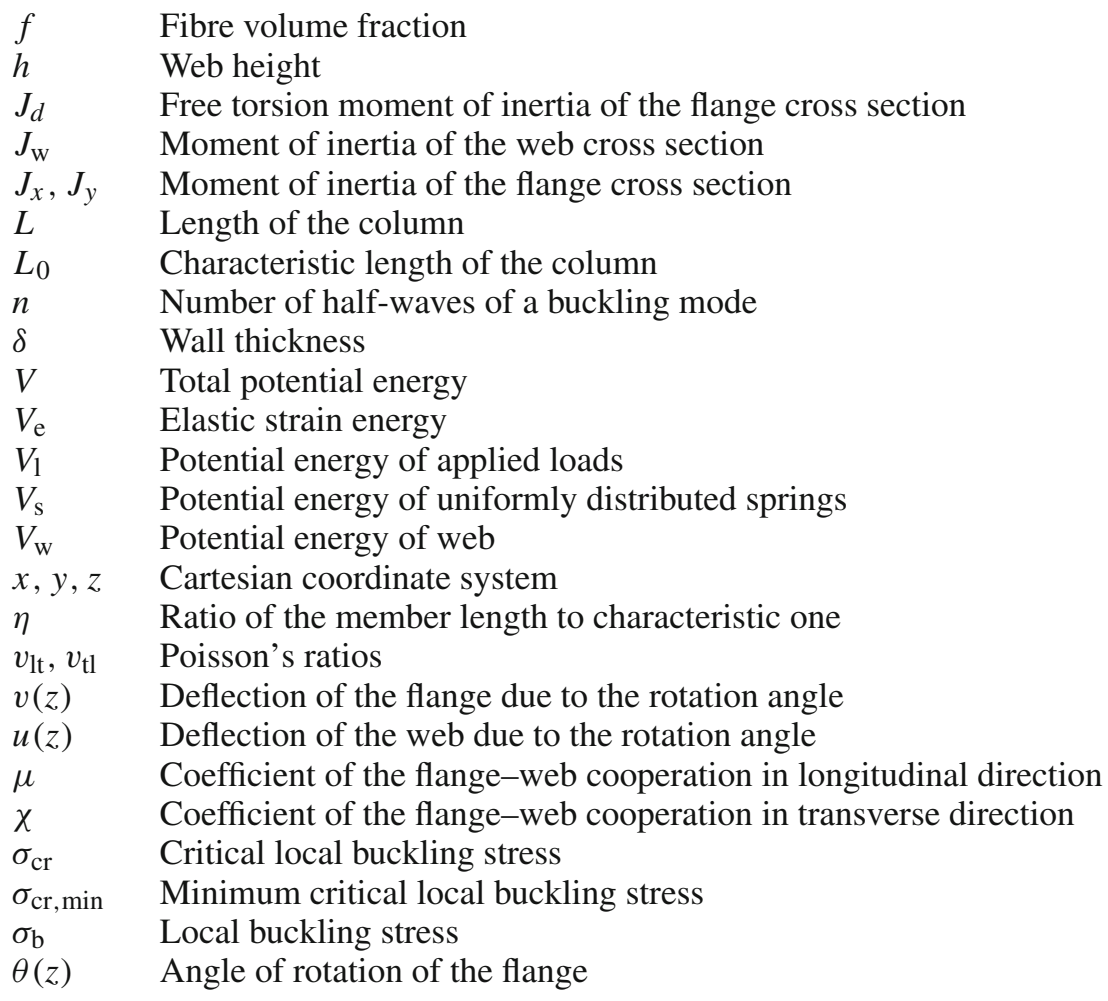

\section{Introduction}

Thin-walled members made of particulate, flake and fibre composites are increasingly applied in engineering problems (aerospace structures, military and civilian aircraft, transportation industry, ship structures, etc.) [4]. The main reasons for the application of composite structures are low cost, high strength and simple manufacturing process. Unfortunately, there are drawbacks or limitations to use fibre composites [14]. The advantages and disadvantages of mechanical behaviour of composite materials are widely described in many publications $[3,13,15,18,33]$.

In the design of thin-walled channel columns, it is important to fulfil different criteria of stability loss: overall, local and distortional conditions. The problems of different types of buckling and post-buckling, in sense of Generalized Beam Theory (GBT), in elastic range are well described in the literature [22-24,30-32]. In studies is also highlighted the influence of initial geometrical imperfections on buckling behaviour of structures [21,29]. Recent advances in buckling and post-buckling behaviour of composite plates and shells structures subjected to static and dynamic loads [16,17,20,27] and [19] lead to extended applications in engineering. Theoretical and numerical studies of stability problems are verified experimentally too $[1,6,7,25,28]$. Nowadays, the software based on finite element method (FEM) or semi-analytical method (SAM) [7,17] and [5] is applied to solve a variety of stability problems. Nevertheless, in initial structural design, sensitivity analysis or optimal design analytical closed-form solution of specific problems is convenient. Models employed for the analysis of buckling in fibre-reinforced materials are being developed also in the study of fibred sheets, woven fabrics and textiles, pantographic fabrics, elastic nets, etc. $[2,8,10,11,26]$.

The paper focuses on local stability of flanges of axially compressed channel columns accounting for its cooperation with the member web. The column material is assumed to be orthotropic, and its parameters are assessed by two homogenization variants: based on the theory of mixture and periodicity cell or the Voigt-Reuss hypothesis. The total potential energy of the flange is formulated; applying the stationary energy principle, the fundamental differential equation and the natural boundary conditions are derived. Solution of the equation with appropriate boundary conditions leads to closed-form analytical formulas for the critical buckling stress and the corresponding shape of the buckling mode. The formulas to estimate the number of the buckling mode half-waves are presented too. It should be emphasized that the critical stresses obtained are valid only in the elastic range of the column material behaviour. Moreover, it is assumed that the local buckling 


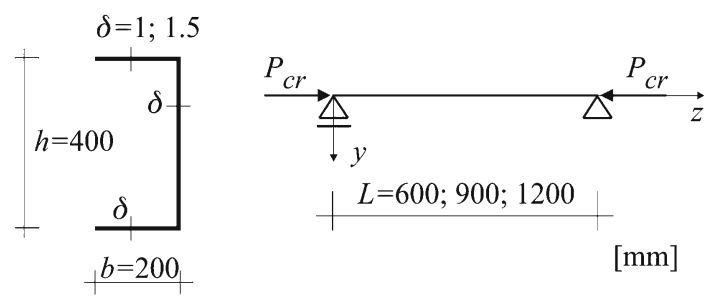

Fig. 1 Thin-walled channel column—numerical example

stresses of flange and web, taken separately, without cooperation, are higher than the critical buckling stress of a compound buckling. Comparative stability analysis results are presented, in accordance with the present formulation and the finite element method, for the column with two values of thickness flange $\delta$. The paper deals with a special type of composite structural columns made of fibre composites with long continuous fibres in one direction (longitudinal direction).

\section{Total potential energy of flange}

Let us consider composite thin-walled channel section column shown in Fig. 1. It is assumed that the column is made of unidirectional fibre-reinforced composite material. Using homogenization, the material is considered orthotropic, and its mechanical properties are based on the theory of mixture and periodicity cell $[3,15,17,18]$ or in accord with the Voigt-Reuss hypothesis [3,17,19].

The description of homogenized orthotropic material for composite plates is based on the theory of mixture and periodicity cell (material model type A) [19]

$$
\begin{aligned}
& E_{\mathrm{l}}=E_{\mathrm{m}}(1-f)+E_{\mathrm{f}} f \\
& E_{\mathrm{t}}=E_{\mathrm{m}} \frac{E_{\mathrm{m}}(1-\sqrt{f})+E_{\mathrm{f}} \sqrt{f}}{E_{\mathrm{m}}[1-\sqrt{f}(1-\sqrt{f})]+E_{\mathrm{f}} \sqrt{f}(1-\sqrt{f})} \\
& G=G_{\mathrm{m}} \frac{G_{\mathrm{m}} \sqrt{f}(1-\sqrt{f})+G_{\mathrm{f}}[1-\sqrt{f}(1-\sqrt{f})]}{G_{\mathrm{m}} \sqrt{f}+G_{\mathrm{f}}(1-\sqrt{f})} \\
& v_{\mathrm{lt}}=v_{\mathrm{m}}(1-\sqrt{f})+v_{\mathrm{f}} \sqrt{f} \\
& E_{\mathrm{l}} v_{\mathrm{tl}}=E_{\mathrm{t}} v_{\mathrm{lt}}
\end{aligned}
$$

where $E_{1}, E_{\mathrm{t}}$-Young's modulus in longitudinal and transverse direction for composite material, $E_{\mathrm{m}}, E_{\mathrm{f}}-$ Young's modulus for matrix and fibre, $G$-homogenized shear modulus, $G_{\mathrm{m}}, G_{\mathrm{f}}$ - shear modulus for matrix and fibre, $v_{\mathrm{m}}, v_{\mathrm{f}}$-Poisson's ratios for matrix and fibre, $v_{\mathrm{l}}, v_{\mathrm{t}}$-Poisson's ratios in longitudinal and transverse direction, and $f$-fibre volume fraction. Another simple homogenization method based on the Voigt-Reuss hypothesis (material model type B) [3,19] is characterized by

$$
\begin{aligned}
& E_{\mathrm{l}}=E_{\mathrm{m}}(1-f)+E_{\mathrm{f}} f \\
& E_{\mathrm{t}}=\frac{E_{\mathrm{f}} E_{\mathrm{m}}}{E_{\mathrm{f}}-E_{f} f+E_{\mathrm{m}} f} \\
& G=\frac{G_{\mathrm{f}} G_{\mathrm{m}}}{G_{\mathrm{f}}-G_{f} f+G_{\mathrm{m}} f} \\
& v_{\mathrm{lt}}=v_{\mathrm{m}}(1-f)+v_{\mathrm{f}} f \\
& E_{\mathrm{l}} v_{\mathrm{tl}}=E_{\mathrm{t}} v_{\mathrm{lt}}
\end{aligned}
$$

Due to plane stress, the Young's modulus values in both directions should be modified

$$
\begin{aligned}
& D_{\mathrm{l}}=\frac{E_{1}}{1-v_{\mathrm{lt}} v_{\mathrm{tl}}}=E_{1} \frac{1}{1-\frac{E_{\mathrm{t}}}{E_{1}} v_{\mathrm{lt}}^{2}} \\
& D_{\mathrm{t}}=E_{\mathrm{t}} \frac{1}{1-\frac{E_{\mathrm{t}}}{E_{1}} v_{\mathrm{lt}}^{2}}
\end{aligned}
$$




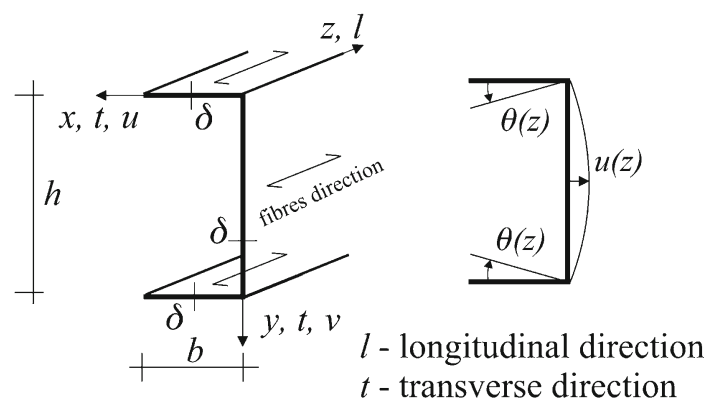

Fig. 2 Cartesian coordinate system and flange displacement

Local buckling of the compressed flange is related to rotation of the flange about the axis corresponding to the line of the flange and web connection. The flange is considered a long thin-walled beam elastically supported by uniformly distributed springs along the flange-web connection modelling the cooperation. In the case of axially compressed column, the cross section in the buckling mode is symmetrical. Let us assume the Cartesian coordinate system $(x, y, z)$ located at the point of the flange-web connection. The displacement $v(z)$ of an arbitrary point $x$ of the flange may be related to rotation angle (Fig. 2)

$$
v(z)=x \theta(z)
$$

The total potential energy of the column $V$ is a sum of the elastic strain energy of the flanges $V_{\mathrm{e}}$, the elastic energy of the web $V_{\mathrm{w}}$, the elastic energy of uniformly distributed springs along the flange-web connection $V_{\mathrm{s}}$ and the potential energy of the external stresses uniformly distributed in the end cross section $V_{1}$

$$
V=V_{\mathrm{e}}+V_{\mathrm{w}}+V_{\mathrm{s}}+V_{\mathrm{l}}
$$

The elastic strain energy of the flange of length $L$ may be expressed as a sum of the energy related to the bending and free torsion of the flange

$$
\begin{aligned}
V_{\mathrm{e}} & =\frac{1}{2} D_{\mathrm{l}} J \int_{0}^{L} \theta^{\prime \prime 2} \int_{0}^{b} x^{2} \mathrm{~d} x \mathrm{~d} z+\frac{1}{2} G J_{d} \int_{0}^{L} \theta^{\prime 2} \mathrm{~d} z \\
& =\frac{1}{6} D_{1} J b^{3} \int_{0}^{L} \theta^{\prime \prime 2} \mathrm{~d} z+\frac{1}{2} G J_{d} \int_{0}^{L} \theta^{\prime 2} \mathrm{~d} z
\end{aligned}
$$

where $D_{1}, G$ stand for the elasticity in longitudinal direction and shear modulus, respectively, primes denote differentiation with respect to $z, J_{d}$ is the flange free torsion moment of inertia and $J=\frac{\delta^{3}}{12}$ describes moment of inertia of a unit part of the wall.

The deflection of the web due to the same rotation angle at both its ends (Fig. 2) is

$$
u(z)=\theta(z) y\left(1-\frac{y}{h}\right)
$$

where $h$ is the web depth.

Thus, the elastic potential energy of the web is

$$
V_{\mathrm{w}}=\frac{1}{2} D_{\mathrm{l}} J \int_{0}^{L} \theta^{\prime \prime 2} \int_{0}^{h} y^{2}\left(1-\frac{y}{h}\right)^{2} \mathrm{~d} y=\frac{1}{60} D_{\mathrm{l}} \bar{J} h^{3} \int_{0}^{L} \theta^{\prime \prime 2}
$$

The potential energy of uniformly distributed elastic springs accounting for cooperation of the flange with the web in transverse direction is expressed as follows:

$$
V_{\mathrm{s}}=\frac{1}{2} k_{\theta} \int_{0}^{L} \theta^{2} \mathrm{~d} z
$$

where $k_{\theta}$ is the stiffness of the springs defined as

$$
k_{\theta}=\chi \frac{D_{\mathrm{t}} J_{w}}{h}
$$


where $D_{\mathrm{t}}$ is the elasticity modulus in transverse direction and $J_{w}$ describes a unit part of the web cross-section moment of inertia and the coefficient $\chi=2$. The potential energy of the applied external stresses $\sigma_{0}$ on the column end cross-section takes the form

$$
V_{1}=-\frac{1}{2} \sigma_{0} \int_{0}^{L}\left(2 \int_{0}^{b} v^{\prime 2} \delta \mathrm{d} x+\int_{0}^{h} u^{\prime 2} \delta \mathrm{d} y\right) \mathrm{d} z .
$$

Substituting the relations (4) and (7) for columns into (11) leads to

$$
\begin{aligned}
V_{1} & =-\frac{1}{2} \sigma_{0} \delta \int_{0}^{L} \theta^{\prime 2} \mathrm{~d} z\left(2 \int_{0}^{b} x^{2} \mathrm{~d} x+\int_{0}^{h} u^{2} \mathrm{~d} y\right) \\
& =-\frac{1}{2} \sigma_{0} \bar{J}_{y} \int_{0}^{L} \theta^{\prime 2} \mathrm{~d} z
\end{aligned}
$$

where

$$
\begin{aligned}
\bar{J}_{y} & =\frac{1}{3} \delta b^{3}\left(2+0.1\left(\frac{h}{b}\right)^{3}\right)=\mu J_{y} \\
J_{y} & =\frac{1}{3} \delta b^{3}
\end{aligned}
$$

where $J_{y}$ stands for the flange moment of inertia about $y$ axis (see Fig. 2) and the coefficient

$$
\mu=2+0.1\left(\frac{h}{b}\right)^{3}
$$

is introduced.

The total potential energy, a sum of all partial energies, equals

$$
V=\frac{1}{2} \int_{0}^{L}\left[D_{\mathrm{l}} J \mu b^{2} \theta^{\prime \prime 2}+\left(2 G J_{d}-\sigma_{0} \mu J_{y}\right) \theta^{\prime 2}+2 \chi \frac{D_{\mathrm{t}} J_{w}}{h} \theta^{2}\right] \mathrm{d} z
$$

\section{Governing differential equation and its solution}

The principle of stationary total potential energy (15) [9] leads to the governing differential equation of the problem

$$
D_{1} \mu J b^{2} \theta^{\prime \prime \prime \prime}+\left(\sigma_{0} \mu J_{y}-2 G J_{d}\right) \theta^{\prime \prime}+2 \chi \frac{D_{\mathrm{t}} J_{w}}{h} \theta=0
$$

and the suitable natural boundary conditions for both member ends for $i=0$ or $L$

$$
\begin{aligned}
\theta(i)=0 & \text { or } \quad\left(2 G J_{d}-\sigma_{0} \mu J_{y}\right) \theta^{\prime}(i)-D_{\mathrm{l}} \mu J b^{2} \theta^{\prime \prime \prime}(i)=0 \\
\theta^{\prime}(i)=0 & \text { or } \quad \theta^{\prime \prime}(i)=0
\end{aligned}
$$

Equation (17) may be rewritten as

$$
\theta^{\prime \prime \prime \prime}+2 \alpha \theta^{\prime \prime}+\beta^{2} \theta=0
$$

where

$$
\begin{aligned}
\alpha & =\frac{\sigma_{0} \mu J_{y}-2 G J_{d}}{2 D_{1} J \mu b^{2}} \\
\beta^{2} & =2 \chi \frac{D_{\mathrm{t}} J_{w}}{D_{1} \mu h J b^{2}}
\end{aligned}
$$

Solution of the Eq. (19) is

$$
\theta(z)=C_{1} \sin \left(t_{1} z\right)+C_{2} \cos \left(t_{1} z\right)+C_{3} \sin \left(t_{2} z\right)+C_{4} \cos \left(t_{2} z\right)
$$

where

$$
\begin{aligned}
& t_{1}=\alpha^{0.5}\left\{1-\left[1-\left(\frac{\beta}{\alpha}\right)^{2}\right]^{0.5}\right\}^{0.5} \\
& t_{2}=\alpha^{0.5}\left\{1+\left[1-\left(\frac{\beta}{\alpha}\right)^{2}\right]^{0.5}\right\}^{0.5}
\end{aligned}
$$

The constants $C_{1}, C_{2}, C_{3}$ and $C_{4}$ should be determined from the appropriate boundary conditions. 


\section{Simply supported column}

Numerical examples are related to simply supported channel column of length $L$ presented in Fig. 1. Using the boundary conditions

$$
\begin{array}{ccc}
z=0 & \theta=0, & \theta^{\prime \prime}=0 \\
z=L & \theta=0, & \theta^{\prime \prime}=0
\end{array}
$$

one can calculate $C_{1}=C_{2}=C_{4}=0$, and finally an equation reads

$$
C_{3}\left(t_{1}^{2}-t_{2}^{2}\right) \sin \left(t_{2} L\right)=0
$$

Local buckling may occur if $C_{3} \neq 0$, hence

$$
\sin \left(t_{2} L\right)=0
$$

Applying this Eq. (21) and relations (24), the stress $\sigma_{b}$ may be determined as a function of number $n$ of half-wave buckling mode

$$
\sigma_{b}=\frac{D_{1}}{J_{y}}\left\{b^{2} J\left[\left(\frac{n \pi}{L}\right)^{2}+\left(\frac{\beta L}{n \pi}\right)^{2}\right]+2 \frac{G J_{d}}{\mu D_{1}}\right\}
$$

Using relations (19), formula (25) may be simplified to

$$
\sigma_{b}=D_{\mathrm{l}}\left(\frac{\delta}{b}\right)^{2}\left[\frac{1}{12} n^{2} \pi^{2}\left(\frac{b}{L}\right)^{2} \frac{D_{\mathrm{t}}}{2 D_{\mathrm{l}} \mu} \chi n^{-2} \pi^{-2}\left(\frac{L}{b}\right)\left(\frac{L}{h}\right)+\frac{2 G}{\mu D_{\mathrm{l}}}\right]
$$

In order to find the critical buckling stress, the integer number of half-wave buckling mode $\mathrm{n}$ should be chosen to give a minimum value of the stress (26). Buckling stress (26) is considered a function of the column length $L$, and its minimum is investigated.

The necessary condition for the stress extreme

$$
\frac{\mathrm{d} \sigma_{b}}{\mathrm{~d} L}=0
$$

leads to the column length values to show minimum critical stress

$$
L=\eta L_{0}
$$

where

$$
L_{0}=\pi b \sqrt[4]{\frac{D_{1} h \mu}{6 D_{\mathrm{t}} \chi b}}
$$

is the characteristic member length and the ratio of the column length to the characteristic length $\eta=L / L_{0}$ is introduced.

Substituting the results (29) into relation (26), it is possible to find a minimum critical buckling stress assuming characteristic column lengths independent of the number of half-waves

$$
\sigma_{\mathrm{cr}, \min }=2 D_{\mathrm{l}}\left(\frac{\delta}{b}\right)^{2}\left[\left(\frac{D_{\mathrm{t}} \chi b}{24 D_{\mathrm{l}} h \mu}\right)^{0.5}+\frac{G}{\mu D_{\mathrm{l}}}\right]
$$

The relation of the critical buckling stress vs. the relative member length is shown graphically in Fig. 3 . In conclusion, to determine the value of buckling critical stress, first it is necessary to find the value of coefficient of characteristic length of the column $\eta$ and next use Fig. 3 to read the number of half-waves $n$. After substitution of the number of half-waves $n$ into (26), we obtain the critical buckling stress sought. 


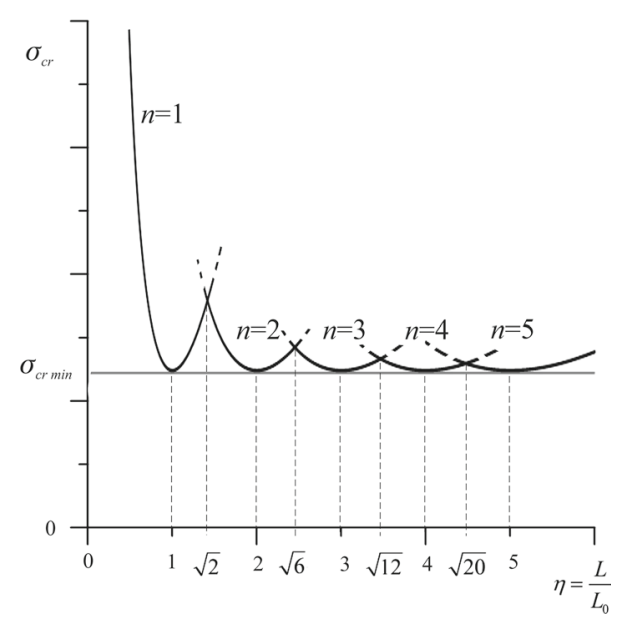

Fig. 3 Critical buckling stress versus column length scaled by characteristic length

Table 1 Material properties for matrix and fibres

\begin{tabular}{lll}
\hline & Epoxy matrix & Glass fibres \\
\hline Density & $1246 \mathrm{~kg} / \mathrm{m}^{3}$ & $2450 \mathrm{~kg} / \mathrm{m}^{3}$ \\
Young's modulus & $3.5 \mathrm{GPa}$ & $71 \mathrm{GPa}$ \\
Kirchoff's modulus & $1.25 \mathrm{GPa}$ & $30 \mathrm{GPa}$ \\
Poisson ratio & 0.33 & 0.22 \\
\hline
\end{tabular}

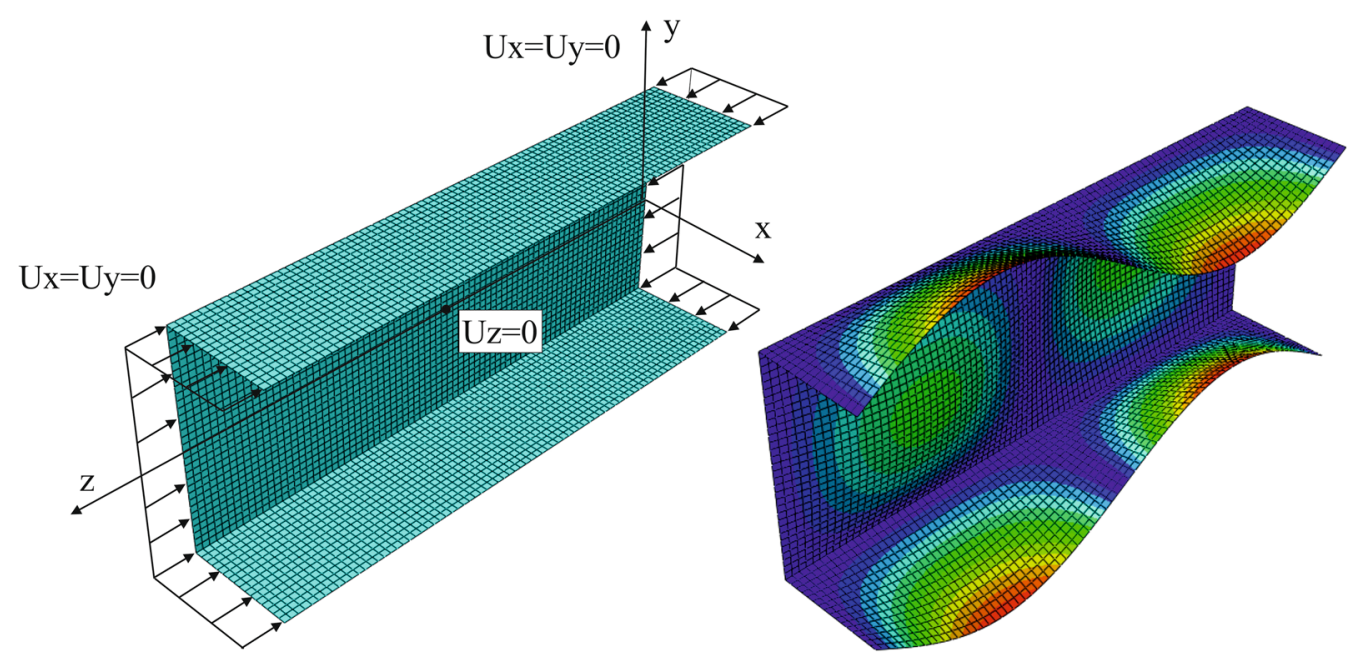

Fig. 4 Two-dimensional finite element models, boundary conditions and load diagrams for axially compressed columns and an example of buckling mode at $n=2$

\section{Numerical examples}

Let us consider columns made of unidirectional fibre-reinforced composite material shown in Fig. 1. The properties for epoxy matrix and glass fibres are presented in Table 1.

The numerical examples are related to axially compressed simply supported columns considered in the previous chapter. Finite element models are shown in Fig. 4. Numerical analysis is conducted in ABAQUS code [12]. In order to estimate the critical buckling loads, a linear perturbation procedure (LBA) is used. The columns are modelled by fully integrated finite membrane-strain shell elements with reduced integration type-S4R. The main finite element size is $0.01 \times 0.01 \mathrm{~m}^{2}$, i.e. 80 elements along the cross section. The total amount of finite elements in all cases equals: 4800 at $L=0.6 \mathrm{~m}, 7200$ at $L=0.9 \mathrm{~m}$ and 9600 at $L=1.2 \mathrm{~m}$. In 
Table 2 Material parameters for model types $\mathrm{A}$ and $\mathrm{B}$ at different fibre volume fraction $f$

\begin{tabular}{|c|c|c|c|c|c|c|c|}
\hline \multirow[t]{3}{*}{$f$} & \multirow{2}{*}{$\begin{array}{l}\text { Material's homogenization } \\
\text { type } \\
\text { A B }\end{array}$} & \multicolumn{2}{|c|}{$\begin{array}{l}\text { Material's homogenization } \\
\text { type }\end{array}$} & \multicolumn{2}{|c|}{$\begin{array}{l}\text { Material's homogenization } \\
\text { type }\end{array}$} & \multicolumn{2}{|c|}{$\begin{array}{l}\text { Material's homogenization } \\
\text { type }\end{array}$} \\
\hline & & $\mathrm{A}$ & $\mathrm{B}$ & & $\mathrm{B}$ & $\mathrm{A}$ & $\mathrm{B}$ \\
\hline & $E_{1}[\mathrm{GPa}]$ & $E_{\mathrm{t}}[\mathrm{GPa}$ & & $G[\mathrm{GP}$ & & $v_{\mathrm{lt}}[-]$ & \\
\hline 0.2 & 17.000 & 5.841 & 4.322 & 1.669 & 1.546 & 0.281 & 0.308 \\
\hline 0.4 & 30.500 & 8.424 & 5.648 & 2.466 & 2.027 & 0.260 & 0.286 \\
\hline 0.6 & 44.000 & 12.774 & 8.148 & 4.039 & 2.941 & 0.245 & 0.264 \\
\hline 0.8 & 57.500 & 22.642 & 14.618 & 7.959 & 5.357 & 0.232 & 0.242 \\
\hline
\end{tabular}

Fig. 4, numerical models, schematic FEM mesh, load and imposed boundary conditions are shown. Material behaviour is modelled by linear elastic orthotropic lamina-type procedure available in ABAQUS [12]. The value parameters of material types A and B $\left(E_{1}=E_{1}, E_{2}=E_{\mathrm{t}}, v_{12}=v_{\mathrm{lt}}, G_{12}=G_{13}=G_{23}=G\right.$ and $\left.v_{21}=\left(E_{2} / E_{1}\right) v_{12}\right)$ are determined by Eqs. (1) and (2), respectively. Furthermore, the values of material parameters are shown in Table 2.

The critical buckling stresses and the corresponding number of half-waves for the columns are presented in Table 3 for $\delta=1$ and $\delta=1.5 \mathrm{~mm}$. The differences between the proposed analytical solutions and the numerical FEM solutions are unsignificant from an engineering point of view, and their relative mean value is $10 \%$. This difference seems constant and independent of the numerical example. A correction factor $\psi$ of critical buckling stress (27) is therefore proposed. The value of the correction factor $\psi$ should be equal to 1.1. Furthermore, the results summarized in Table 3 are shown in Figs. 7 and 8. This proposal is confirmed by the results of an extra numerical analysis at any other geometry and material parameters. Given geometrical parameters: $L=1.8 \mathrm{~m}, b=0.1 \mathrm{~m}, h=0.3 \mathrm{~m}, \delta=1.25 \mathrm{~mm}$ and typical unidirectional reinforced composite materials: boron-epoxy: $E_{1}=207 \mathrm{GPa}, E_{\mathrm{t}}=21 \mathrm{GPa}, G=7 \mathrm{GPa}, v_{\mathrm{lt}}=0.3$, graphite-epoxy: $E_{1}=207 \mathrm{GPa}$, $E_{\mathrm{t}}=5 \mathrm{GPa}, G=2.6 \mathrm{GPa}, v_{\mathrm{lt}}=0.25$, aramid-epoxy: $E_{\mathrm{l}}=76 \mathrm{GPa}, E_{\mathrm{t}}=5.5 \mathrm{GPa}, G=2.1 \mathrm{GPa}, v_{\mathrm{lt}}=0.34$ [13], the critical buckling stresses and the number of half-waves $n$ are shown in Table 4.

The minimum critical stress versus fibre volume fraction $f$ at different values of wall thickness are shown in Fig. 5.

Furthermore, the characteristic member length versus the fibre volume fraction for both material homogenization types are shown in Fig. 6.

\section{Conclusions}

The work concerns local buckling of axially compressed channel columns made of unidirectional fibrereinforced laminate. The closed-form analytical formulas for critical buckling stresses and corresponding buckling modes and the minimum critical stresses independent of the number of half-waves are derived here. Stability analysis is carried out assuming four values of fibre volume fraction: 0.2, 0.4, 0.6 and 0.8 and for three member lengths: $0.6,0.9$ and $1.2 \mathrm{~m}$ in order to estimate the impact of these parameters to the critical buckling stresses. Furthermore, additional analysis is performed for different materials [13] and random structural geometry. The following conclusions are drawn:

- The minimum critical stress values are slightly affected by the type of material homogenization method (material model type A [19] and type B [3] and [19]) (see Fig. 5). In the case of the theory of mixture and periodicity cell (material model type A) greater values of the minimum values of the critical stress occur than in case of simple method of homogenization (material model type B), the difference is not high,

- The critical buckling stresses increase in accord with the fibre volume fraction that increases similarly as the minimum critical one,

- The characteristic length depends significantly on the type of material homogenization method (material model type A [19] and type B [3] and [19]). In the case of simple homogenization method based on the Voigt-Reuss hypothesis (material model type B), the characteristic length is visibly greater than in the case of the theory of mixture and periodicity cell (material model type A) (see Fig. 6), 


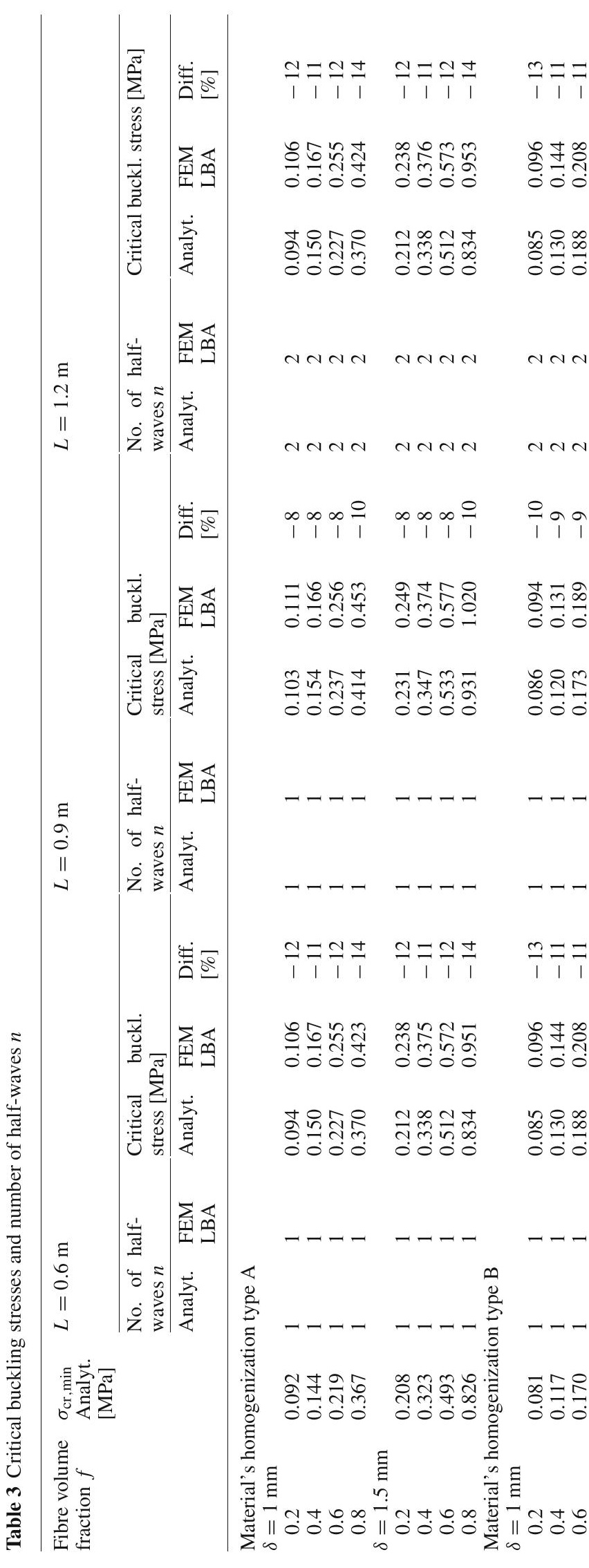


Table 4 Critical buckling stresses and number of half-waves $n$-extra numerical examples

\begin{tabular}{|c|c|c|c|c|c|c|c|c|}
\hline \multicolumn{9}{|c|}{$L=8 \mathrm{~m}, h=0.3 \mathrm{~m}, b=0.1 \mathrm{~m}, \delta=1.25 \mathrm{~mm}$} \\
\hline \multirow[t]{3}{*}{ Material type } & \multirow{3}{*}{$\begin{array}{l}\sigma_{\mathrm{cr}, \min } \\
\text { Analyt. } \\
{[\mathrm{MPa}]}\end{array}$} & \multicolumn{2}{|c|}{ No. of half-wave $n$} & \multicolumn{5}{|c|}{ Critical buckl. stress [MPa] } \\
\hline & & \multirow[t]{2}{*}{ Analyt. } & \multirow[t]{2}{*}{ FEM LBA } & \multicolumn{2}{|l|}{ Analyt. } & \multirow[t]{2}{*}{ FEM LBA } & \multicolumn{2}{|c|}{ Diff. [\%] } \\
\hline & & & & $\psi=1$ & $\psi=1.1$ & & $\psi=1$ & $\psi=1.1$ \\
\hline Boron-Epoxy & 2.064 & 3 & 3 & 2.068 & 2.275 & 2.295 & -11 & -1 \\
\hline Graphite-Epoxy & 0.947 & 2 & 2 & 0.957 & 1.053 & 1.011 & -6 & 4 \\
\hline Aramid-Epoxy & 0.635 & 3 & 2 & 0.637 & 0.701 & 0.708 & -11 & -1 \\
\hline
\end{tabular}

(a)

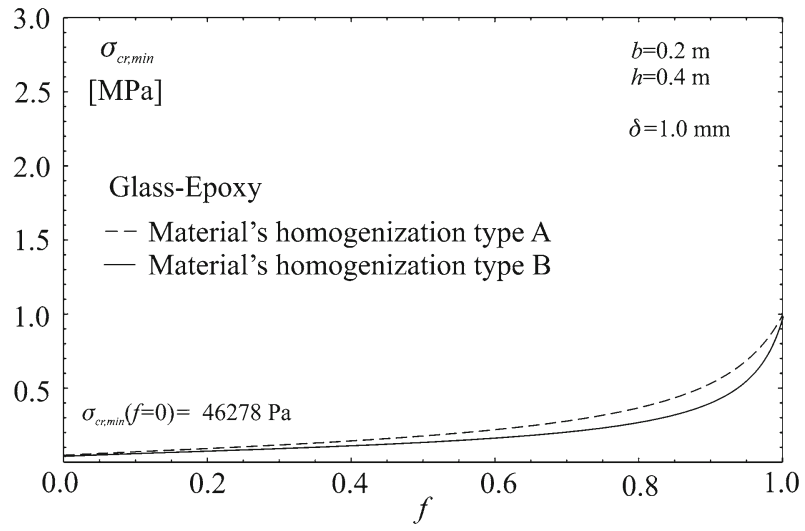

(b)

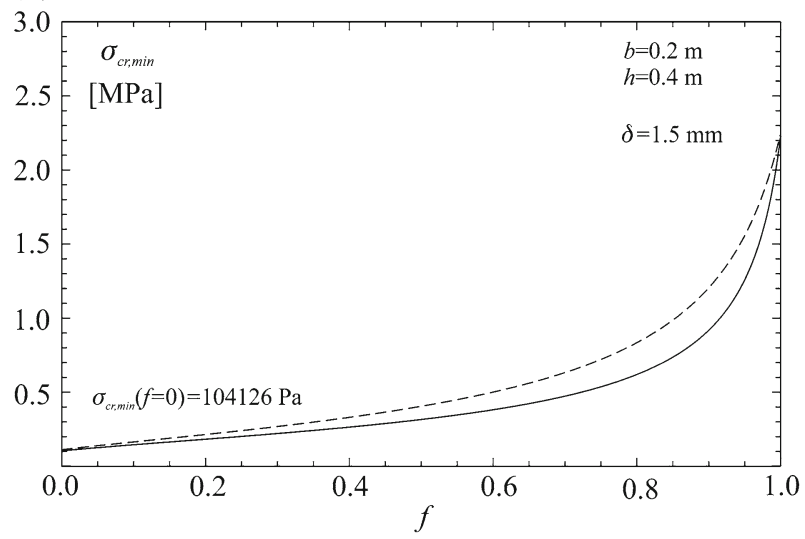

Fig. 5 Minimum critical stresses versus fibre volume fraction $f$ for walls thickness $\mathbf{a} \delta=1.0 \mathrm{~mm}$ and $\mathbf{b} \delta=1.5 \mathrm{~mm}$

- Comparison of analytical and numerical results shows the maximum discrepancies reach $11 \%$ and average below $10 \%$. It should be emphasized that the critical stresses computed analytically are lower than the FEM analysis results. It means safe estimation of critical stresses. The same discrepancies between the analytical and numerical results in all considered cases triggered simplification of the stress field in theoretical analysis, and they may be removed introducing a correcting coefficient $\psi=1.1$. The proposed correcting coefficient is validated by stability analysis application for other random geometric and material properties, complementing the cases presented before, with positive results. 


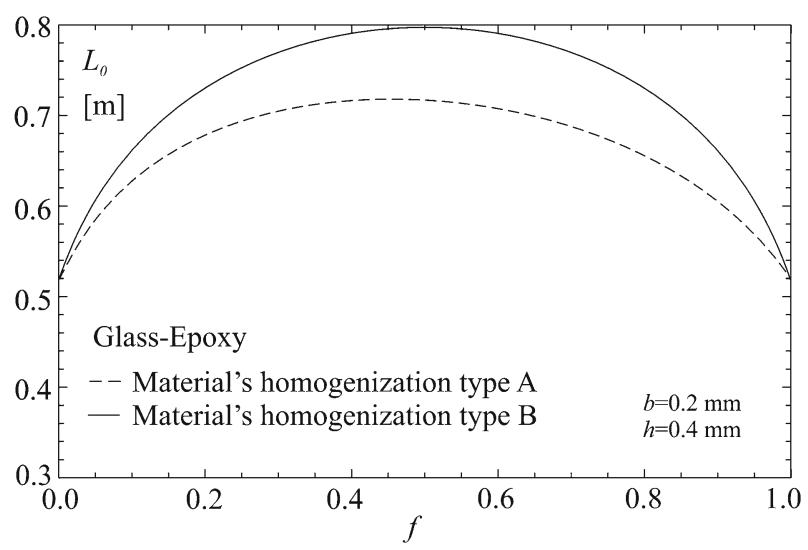

Fig. 6 Characteristic member length versus fibre volume fraction $f$ for both material's homogenization types
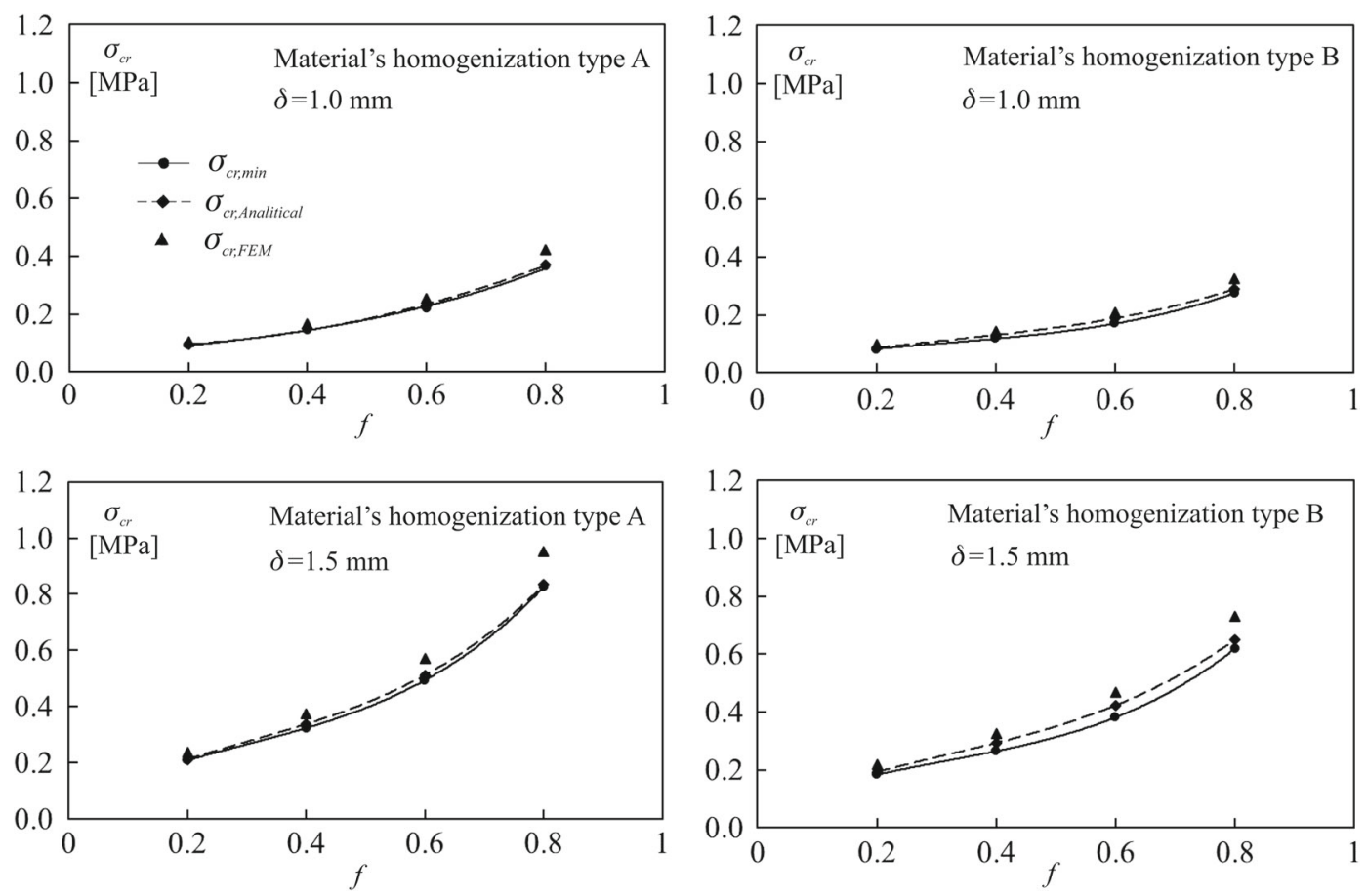

Fig. 7 Critical buckling stress versus fibre volume fraction $f$ for both material homogenization types for $h=0.4 \mathrm{~m}, b=0.2 \mathrm{~m}$ and $L=0.6 \mathrm{~m}$ or $1.2 \mathrm{~m}$ 

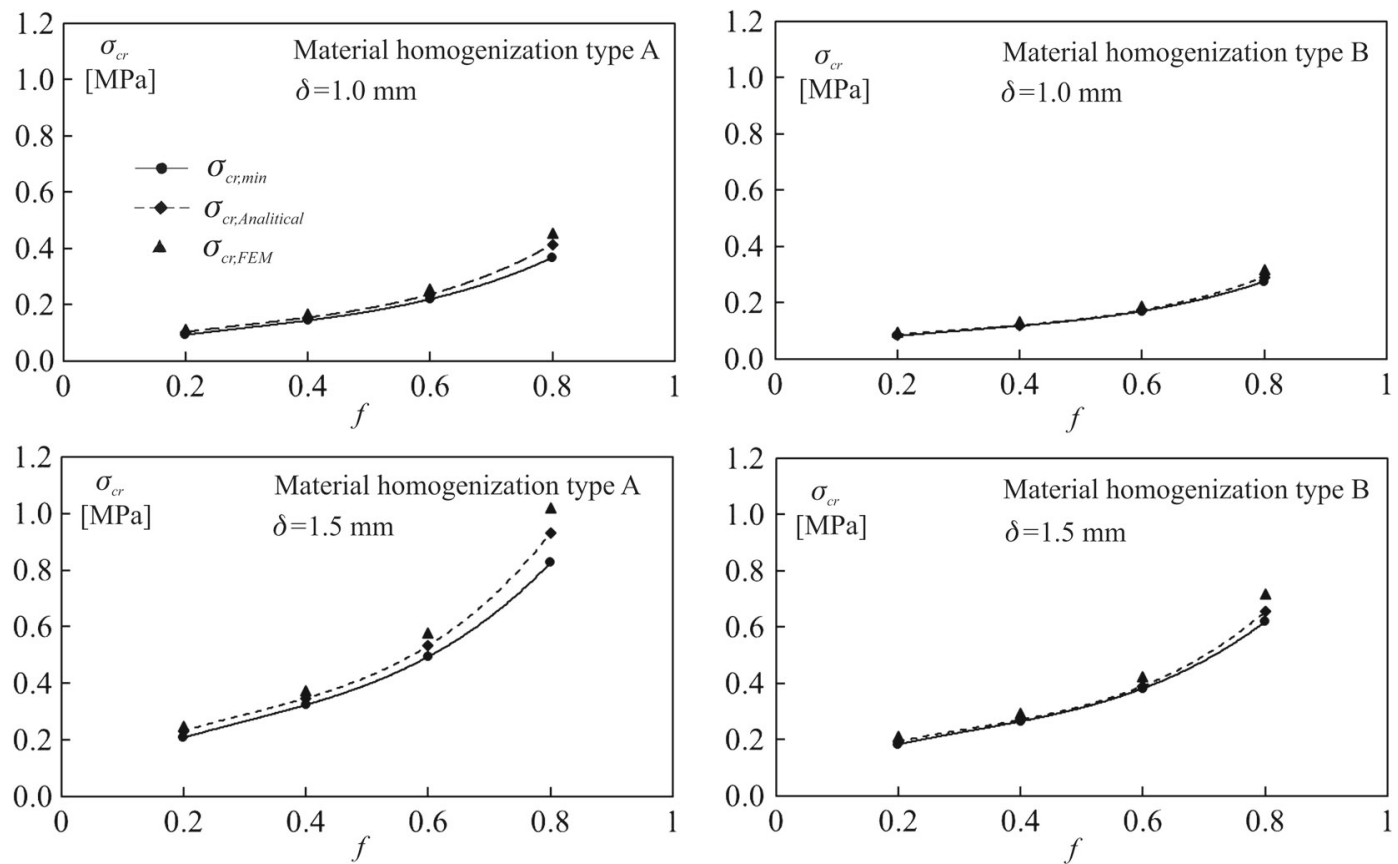

Fig. 8 Critical buckling stresses versus fibre volume fraction $f$ for both material homogenization types for $h=0.4 \mathrm{~m}, b=0.2 \mathrm{~m}$ and $L=0.9 \mathrm{~m}$

Acknowledgements The calculations presented in this paper were carried out at the TASK Academic Computer Centre in Gdańsk, Poland.

\section{Compliance with ethical standards}

Conflict of interest The authors declare that they have no conflict of interest.

Open Access This article is distributed under the terms of the Creative Commons Attribution 4.0 International License (http:// creativecommons.org/licenses/by/4.0/), which permits unrestricted use, distribution, and reproduction in any medium, provided you give appropriate credit to the original author(s) and the source, provide a link to the Creative Commons license, and indicate if changes were made.

\section{References}

1. Bambach, M.: Compression strength of natural fibre composite plates and sections of flax, jute and hemp. Thin-Walled Struct. 119, 103-113 (2017)

2. Barchiesi, E., Ganzosch, G., Liebold, C., Placidi, L., Grygoruk, R., Müller, W.: Out-of-plane buckling of pantographic fabrics in displacement-controlled shear tests: experimental results and model validation. Contin. Mech. Thermodyn. (2018). https:// doi.org/10.1007/s00161-018-0626-x

3. Berthelot, J.: Composite Materials-Mechanical Behaviour and Structural Analysis. Springer, New York (1999)

4. Daniel, L., Ishai, O.: Engineering Mechanics of Composite Materials. Oxford University Press, Oxford (2006)

5. Debski, H., Kubiak, T., Teter, A.: Buckling and post-buckling behaviour of thin-walled composite channel section column. Comput. Struct. 100, 195-204 (2013)

6. Debski, H., Kubiak, T., Teter, A.: Experimental investigation of channel-section composite profiles behavior with various sequences of plies subjected to static compression. Thin-Walled Struct. 71, 147-154 (2013)

7. Debski, H., Kubiak, T., Teter, A.: Numerical and experimental studies of compressed composite columns with complex open cross-sections. Comput. Struct. 118, 28-36 (2014)

8. dell'Isola, F., Steigmann, D.: A two-dimensional gradient-elasticity theory for woven fabrics. J. Elast. 118, 113-125 (2015)

9. Gelfand, I., Fomin, S.: In: Silverman, R.A. (ed.) Calculus of Variations. Selected Russian Publications in the Mathematical Science. Prentice-Hall, Inc., Englewood Cliffs, New Jersey (1963)

10. Giorgio, I., Corte, A.D., del'Isola, F., Steigmann, D.: buckling modes in pantographic lattices. Comptes Rendus Mec. 344(7), 487-501 (2016)

11. Giorgio, I., Rizzi, N.L., Turco, E.: Continuum modelling of pantographic sheets for out-of-plane bifurcation and vibrational analysis. Proc. R. Soc. A Math. Phys. Eng. Sci. 473, 2207 (2017)

12. Habbit, D., Karlsson, B., Sorensen, P.: ABAQUS analysis user's manual. Hibbit, Karlsson, Sorensen Inc

13. Jones, R.: Mechanics of Composites Materials. Taylor \& Francis, Milton Park (1999)

14. Kaw, A.: Mechanics of Composite Materials. Taylor \& Francis, Milton Park (2006) 
15. Kelly, A. (ed.): Concise Encyclopedia of Composite Materials. Pergamon Press, Oxford (1989)

16. Kim, N., Jeon, C.: Coupled static and dynamic analyses of shear deformable composite beams with channel-sections. Mech. Based Des. Struct. Mach. 41, 489-511 (2013)

17. Kołakowski, Z., Kowal-Michalska, K. (eds.): Selected Problems of Instabilities in Composite Structures. A Series Monographs. Technical University of Lodz (1999)

18. Kollar, L., Springer, G.: Mechanics of Composite Structures. Cambridge University Press, Cambridge (2003)

19. Królak, M., Mania, R. (eds.): Stability of Thin-Walled Plate Structures. A Series of Monographs. Lodz University of Technology (2016)

20. Mania, R. (ed.): Buckling of Plate Structures in Analytical, Numerical and Experimental Investigations. A Series of Monographs. Lodz University of Technology (2016)

21. Pignataro, M., Luongo, A.: Asymmetric interactive buckling of thin-walled columns with initial imperfections. Thin-Walled Struct. 5(5), 365-386 (1987)

22. Pignataro, M., Luongo, A., Rizzi, N.: On the effect of the local-overall interaction on the postbuckling of uniformly compressed channels. Thin-Walled Struct. 3(4), 293-321 (1985)

23. Pignataro, M., Rizzi, N., Luongo, A.: Bifurcation, Stability and Postcritical Behaviour of Elastic Structures. Elsevier, Amsterdam (1991)

24. Ranzi, G., Luongo, A.: A new approach for thin-walled member analysis in the framework of GBT. Thin Walled Struct. 49(11), 1404-1414 (2011)

25. Rasheed, H., Al-Musri, R., Alali, B.: Closed form stability solution of simply supported anisotropic laminated composite plates under axial compression compared with experiments. Eng. Struct. 151, 327-336 (2017)

26. Scerrato, D., Giorgio, I., Rizzi, N.: Three-dimensional instabilities of pantographic sheets with parabolic lattices: numerical investigations. Zeitschrift für angewandte Mathematik und Physik 67, 3 (2016)

27. Silvestre, N., Comotim, D.: GBT buckling analysis of pultruded FRP lipped channel members. Comput. Struct. 81, 1889-1904 (2003)

28. Singer, J., Arbocz, J., Weller, T.: Buckling experiments. Experimental methods in buckling of thin-walled structure, vol. 1 and 2. John Wiley \& Sons Inc. (1998, 2002)

29. Szymczak, C., Kujawa, M.: Buckling of thin-walled columns accounting for initial geometrical imperfections. Int. J. NonLinear Mech. 95, 1-9 (2017)

30. Taig, G., Ranzi, G., D'Annibale, F.: An unconstrained dynamic approach for the generalised beam theory. Contin. Mech. Thermodyn. 27(4-5), 879-904 (2015)

31. Taig, G., Ranzi, G., Luongo, A.: GBT pre-buckling and buckling analyses of thin-walled members under axial and transverse loads. Contin. Mech. Thermodyn. 28(1-2), 41-66 (2016)

32. Trahair, N.: Flexural-Torsional Buckling of Structure. E\&FN Spon, London (1993)

33. Vasiliev, V., Morozov, E.: Mechanics and Analysis of Composites Materials. Elsevier, Amsterdam (2001)

Publisher's Note Springer Nature remains neutral with regard to jurisdictional claims in published maps and institutional affiliations. 